\title{
OPTICAL AND ELECTRICAL PROPERTIES OF SILICON SOLAR CELLS BY WET CHEMICAL ETCHING
}

\author{
MAURICIO ARIAS ${ }^{a^{*}}$, MACKARENA BRICEÑO ${ }^{a}$, AITOR MARZO ${ }^{b, c}$, ANTONIO ZÁRATE ${ }^{a}$ \\ ${ }^{a}$ Departamento de Física, Facultad de Ciencias, Universidad Católica del Norte, Avenida Angamos 0610, Casilla 1280, Antofagasta, Chile. \\ ${ }^{b}$ Centro de Desarrollo Energético Antofagasta (CDEA), Universidad de Antofagasta 02800, Casilla 170, Antofagasta, Chile. \\ ${ }^{c}$ Solar Energy Research Center (SERC-Chile), Santiago (Chile)
}

\begin{abstract}
We present a simple method for the texturing of commercial silicon solar cells in a two-step process by etching in an $\mathrm{HF}$ solution containing $\mathrm{H}_{2} \mathrm{O}_{2}$. This etching process is facilitated by silver nanoparticles which act as catalytic sites. The etching times for the fabrication of nano-pores on the surface are established. The optical properties of the nano-structures on the surface of silicon solar cell were investigated by spectrometer measurements. The samples presented a total reflection coefficient lower than that of silicon solar cells without the treatment. The global efficiency of the silicon solar cell depends on the chosen preparation conditions for the silver ion concentration, and time of wet etching. The textured surface of solar cells showed an increase in efficiency, with a circuit photocurrent higher than that of a reference silicon solar cell without texturing. The $J-V$ curves of various silicon cells are presented and discussed in correlation with the surface morphology.
\end{abstract}

\section{INTRODUCTION}

Light trapping in crystalline silicon solar cells is critical to the absorption of electromagnetic waves, and hence is a major factor in determining the efficiency of these devices. In this sense, the minimization of reflection losses is of crucial importance in obtaining high photo-conversion in solar cells. Photovoltaic cells normally require special surface structures or additive materials, which can reduce reflectance. The standard method for enhancing absorption in a solar cell is to employ geometric scattering at one or both of the surfaces which form the boundaries between the active layers. The use of antireflection coating (ARC), based on destructive interference of light, is generally used to reduce the reflection in solar cell devices. The use of nanostructures such as porous silicon is suitable for use as an ARC in solar devices [1]. A number of approaches have been developed for this purpose, and in many cases, through the texturization of the surface[2]. Nanostructures can be fabricated by a variety of methods, such as vapour-liquid-solid (VLS) growth [3], reactive ion etching (RIE) [4], focused ion beam lithography (FIB) [5], electrochemical etching [6], laser modification [7] and metal-assisted chemical etching (MACE) [8]. Among these methods, metal-assisted etching is particularity promising due to its simplicity, versatility, and low cost. Metalassisted etching can be done without the use of vacuum processes, which can significantly reduce the manufacturing costs of solar cells [9]. Silicon with nanostructures exhibits high absorption over a wide spectral range, from 250 - $2500 \mathrm{~nm}$. MACE techniques provide a method for obtaining various silicon nanostructures, such as Si nanowires and $\mathrm{Si}$ nano-pores with well-controlled morphological characteristics. It is known that metallic nanoparticles attached to a silicon surface have a greater electronegativity than that of the silicon. For this reason, the nanoparticles attract electrons and become negatively charged. During the etching process, $\mathrm{Ag}$ particles can be converted into $\mathrm{Ag}^{+}$by hydrogen peroxide [10]. It has been established that silver has a better performance for etching compared to other metals such as $\mathrm{Au}, \mathrm{Pt}$ or $\mathrm{Cu}$.

In addition to their use for etching in MACE method, the use of metallic nanoparticles is one of the most promising approaches to address the light absorption. The contribution in the enhanced of light absorption can be attributed to SPR (surface plasmon resonance). Incident light is strongly scattered and absorbed, and the magnitude of these effects depends on the size and shape of the metallic nanoparticles (NP's). This improvement in the optical absorption of the incident photons can be expected due to the trapping of optical waves near the surface due to the collective surface oscillation of conducting electrons in metallic nanoparticles [11].

In this way, silver nanoparticles can be used to scatter electromagnetic waves very efficiently and produce trapped modes for the light within the semiconductor region near the nanoparticles. This trapping can be achieved by the appropriate fabrication procedure $[12,13]$. The use of porous silicon and silver nanoparticles in silicon solar devices may be a promising method to increase in conversion efficiency through a combination of reduced effective reflection coefficient and light capture.

In this article, we present a simple low-cost wet chemical etching process which is facilitated by the presence of silver metal clusters, and is applied to n-type (100) Si and commercial silicon solar cells. The sample processing is performed in two steps: firstly by controlling the formation of metallic particle via the immersion time in the metallic salt solution (step 1), and secondly by controlling the etching time (step 2). The texturing of the surface can be achieved with different depths over a large scale, depending on the etching parameters. This etching process is a relatively simple and inexpensive process which promises to increase the efficiency of photovoltaic devices.

\section{EXPERIMENTAL PROCEDURES}

\subsection{Material}

All reactions were carried out at room temperature. $\mathrm{AgNO}_{3}$ (sigmaAldrich, $\mathrm{HF}$ (48\%, Sigma-Aldrich), $\mathrm{H}_{2} \mathrm{O}$ (30\%, Merck) were used as received. Polished, single-crystalline (100) n-type arsenic-doped $\mathrm{Si}$ wafers with a resistivity of $0.001-0.005 \Omega \mathrm{cm}$, were cleaved into pieces $1.0 \times 1.0 \mathrm{~cm}^{2}$ in area and ultrasonically cleaned in acetone and deionized water for $10 \mathrm{~min}$ at room temperature. Textured monocrystalline silicon solar cells were purchased (Wuxi My Solar Technology Co., Ltd., grade A) and ultrasonically cleaned in acetone and deionized water for $10 \mathrm{~min}$ at room temperature

2.2 Metal-assisted chemical etching onto silicon and commercial silicon solar cells

Wet etching was performed by immersing the Si (100) n-type and silicon solar cell in a mixture of $\mathrm{AgNO}, 5 \% \mathrm{~m} / \mathrm{m}$ and $\mathrm{HF} 5 \mathrm{M}$ at room temperature for a given period time (step 1). The samples were then immersed in a second aqueous solution of $\mathrm{H}_{2} \mathrm{O}_{2} 5 \% \mathrm{~m} / \mathrm{m}$ and $\mathrm{HF} 5 \mathrm{M}$ for a certain time, ranging from $30 \mathrm{~s}$ to $10 \mathrm{~min}$ (step 2 ). Table 1 indicates the times for each experimental step and, the names of the corresponding samples. The samples were washed with deionized water before measurements.

\subsection{Atomic force microscopy}

The morphology of the sample surface was also studied using atomic force microscopy. The AFM images taken from the samples were recorded with a WiTec Alpha 300 AR microscope in AC/tapping and contact mode using a silicon cantilever tip. Image processing of the sample surfaces was performed using the WiTec 2.06 software provided by the manufacturer.

\subsection{X-Ray diffraction}

The X-ray diffraction measurements were performed using a Bruker D8 Advance diffractometer fitted with a graphite monochromator with $\mathrm{Cu} \mathrm{Ka}$ radiation $(\mathrm{k}=1.54057 \AA$ ) across the range from $20 \leq 2 \theta \leq 80$ for the silicon samples.

\subsection{Reflectivity}

Reflectance $(R)$ was measured using a spectrophotometer in total reflectance mode (i.e. including diffuse and specular light) and was used to calculate the absorption (A) $(\mathrm{A}=100 \%-R)$ assuming opaque samples. The instrument measures the spectral reflectance using an integrating sphere, a light source, and a reference sample for reflectance. This instrument operates in the spectral range of 200 to $900 \mathrm{~nm}$, with a resolution of less than $1 \mathrm{~nm}$. 
2.5 J-V Curve

The electrical parameters of the samples, i.e., the J-V curves, were measured using an electrochemical cell, (model VersaStat 4 from Princeton
Research Applied AMETEK) and a solar simulator from Photoemission (model SS50AAA, from Photoemission Tech.) with $300 \mathrm{~W}$, air mass 1.5, and a frequency of $50-60 \mathrm{~Hz}$.

Table 1. Experimental time in both solutions of MACE methods on polished monocrystalline silicon wafers and textured commercial silicon solar cells. The name of the sample used is indicated.

\begin{tabular}{|c|c|c|c|}
\hline Substrate & $\begin{array}{c}\text { Immersion time }[\mathrm{s}] \text { in } \mathrm{AgNO}_{3} 5 \% \mathrm{~m} / \mathrm{m} \text { and } \\
\text { HF } 5 \mathrm{M} \text { solution (step 1) }\end{array}$ & $\begin{array}{c}\text { Etching time }[\mathrm{s}] \text { in } \mathrm{H}_{2} \mathrm{O}_{2} 5 \% \mathrm{~m} / \mathrm{m} \text { and } \\
\text { HF } 5 \mathrm{M} \text { solution (step 2) }\end{array}$ & Sample name* \\
\hline \multirow{5}{*}{ Si-n (100) } & 0 & 0 & $\mathrm{Si}-0 / 0$ \\
\hline & 18 & 0 & Si-18/0 \\
\hline & 18 & 30 & Si-18/30 \\
\hline & 18 & 120 & Si-18/120 \\
\hline & 320 & 0 & $\mathrm{Si}-360 / 0$ \\
\hline \multirow{5}{*}{ Silicon Solar Cell } & 0 & 0 & SC-Ref \\
\hline & 18 & 0 & $\mathrm{SC}-18 / 0$ \\
\hline & 18 & 30 & SC-18/30 \\
\hline & 18 & 120 & SC-18/120 \\
\hline & 18 & 600 & SC-18/600 \\
\hline
\end{tabular}

*Sample X-Y/Z, where $\mathrm{X}=\mathrm{Si}$ (polished silicon wafer) or SC (textured silicon solar cell), Y= immersion time [s] in step 1 and Z= etching time [s] of step 2.

\section{RESULTS AND DISCUSSION}

3.1 Deposition of Ag nanoparticles and formation of Si nano-pores

Silicon and silicon solar cells were etched with HF and an oxidative agent (catalyzed by silver) to obtain a structured surface that allows for light trapping. Here, we use a monocrystalline n-type Si wafer as a substrate with virtually identical properties to a monocrystalline silicon solar cell. In both cases, the etch is performed on the n-type layer. In the etching process, the substrates with the silver particles are immersed in a solution of HF and an oxidative agent.

The MACE method can be explained through two processes which depend on the generation and transport of electronic holes, which are formed through redox reactions at the interface between the silver particle and the electrolyte solution. The silver particle catalyzes the reduction of hydrogen peroxide, which injects holes into the silicon surface. The electrons are taken from $\mathrm{Ag}^{+}$to produce $\mathrm{Ag}$ particles, and the silicon is oxidized into $\mathrm{SiO}_{2}$. Finally, the silicon dioxide is attacked by the $\mathrm{HF}$ and dissolved in the aqueous solution as $\mathrm{SiF}_{6}^{-2}$ [14].

The fabricated Ag particles are then introduced to the silicon wafer and commercial silicon solar cell samples. For this method, the $\mathrm{Ag}^{+}$ion concentration plays a crucial role in forming silver grains, which act as a catalyst in the next step. The silver particles formed on the silicon (100) surface samples exhibit features of density and size that depend on the stoichiometry and on the immersion time in each solution. Under equal chemical conditions, $\mathrm{Ag} / \mathrm{HF}$ solutions concentration and room temperature, all samples show an increase in the size of the metal particle. A similar effect is observed in the second step, with the increase in $\mathrm{H}_{2} \mathrm{O}_{2} / \mathrm{HF}$ etching time, which acts as a hole donor and oxidant agent, showing the most pronounced change in pore size by increasing the immersion time. Yousong and co-workers found a close relationship between the uniformity of the pores formed and low concentrations of hydrogen peroxide [15]. This behavior is related to the low oxidation speed of the $\mathrm{Si}$ around the metal nanoparticles [16].

\subsection{Atomic force microscopy}

By scanning the samples, a topographic image of the surface is recorded and can be used for particle imaging and sizing. The scanning was performed in acoustic mode with a low force amplitude. A scan resolution of $512 \times 512$ was achieved for a surface of $10 \mu \mathrm{m} \times 10 \mu \mathrm{m}$ for the n-type (100) Si. Data acquisition was followed by image processing using the WiTec software and in some cases, horizontal artifact lines were removed. The grain distribution was obtained for several samples. Figure 1 depicts a representative AFM image taken in acoustic mode of silver nanoparticles on n-type (100) $\mathrm{Si}$. The metal particles are homogeneously dispersed on the surface. The metallic nanoparticles show approximately spherical grains, which was established by particle analysis of the AFM topography image. The size distribution is shown in Figure 1a and $1 \mathrm{~b}$. The diameter of the silver nanoparticles on the n-type (100) $\mathrm{Si}$ was significantly influenced by the immersion time in $\mathrm{AgNO}_{3} / \mathrm{HF}$ solution. The histogram shows a distribution of around $79.5 \mathrm{~nm}( \pm 0.1 \mathrm{~nm})$ and 192.0 $\mathrm{nm}( \pm 0.1 \mathrm{~nm})$, at 18 second and 3 minutes of exposition time, respectively. This effect is in agreement with that observed by Bastide and co-workers in terms of size and density of metallic NPs as a function of the exposure time [17]. Figure 2 shows AFM image of a planar view of the nanoporous (100) $\mathrm{Si}$ fabricated by MACE. These silicon wafer samples are immersed in $\mathrm{AgNO}_{3} /$ $\mathrm{HF}$ solution for $18 \mathrm{~s}$, after which the samples are treated in $\mathrm{H}_{2} \mathrm{O}_{2} / \mathrm{HF}$ etching solution for 30, 120 and $600 \mathrm{~s}$. The cross-sectional view of the nanopores in the silicon is shown in Figure 2b. We observed that the roughness of the surface was due to the hydrofluoridric acid on the silicon, and the catalytic process of $\mathrm{Ag}$ particles and the exposed silicon. The results obtained show that the deeper and wider pores are formed with longer duration in the etching solution. Huang and collaborators found that substrates are found to be influenced by the concentration of the oxidant in the etching solution when at low oxidant concentration, and that the etching proceeds along the crystallographically preferred $\langle 100\rangle$ directions [18]. Additionally, Tsujino et al. found that when the $\mathrm{H}_{2} \mathrm{O}_{2}$ concentration was reduced, they no found any preference for growing direction [19]. Figure 2c shows the depth profile for a silicon wafer with $18 \mathrm{~s}$ in the $\mathrm{Ag} / \mathrm{HF}$ solution at three different etching times 30,120 and 600 seconds, respectively (step 2). The pores showed a distribution around of $0.4 \mathrm{~nm}$ at short etching times, and a $1.1 \mathrm{~nm}$ distribution for high etching times. Samples with an etching time of $30 \mathrm{~s}$ exhibit low depth due to the low immersion time. Etching for $600 \mathrm{~s}$ show a pore profile average of $1 \mathrm{~nm}$, is observed that under these conditions the formation of holes up to $5 \mathrm{~nm}$ depth is promoted. On the other hand, silver is known to be easily dissolvable in the acid etching solution, and re-nucleates for further etching, leading to a very textured surface after the etching process [20]. It is also observed that after etching all the samples show pore openings which are larger than the diameter of the silver nanoparticles. 

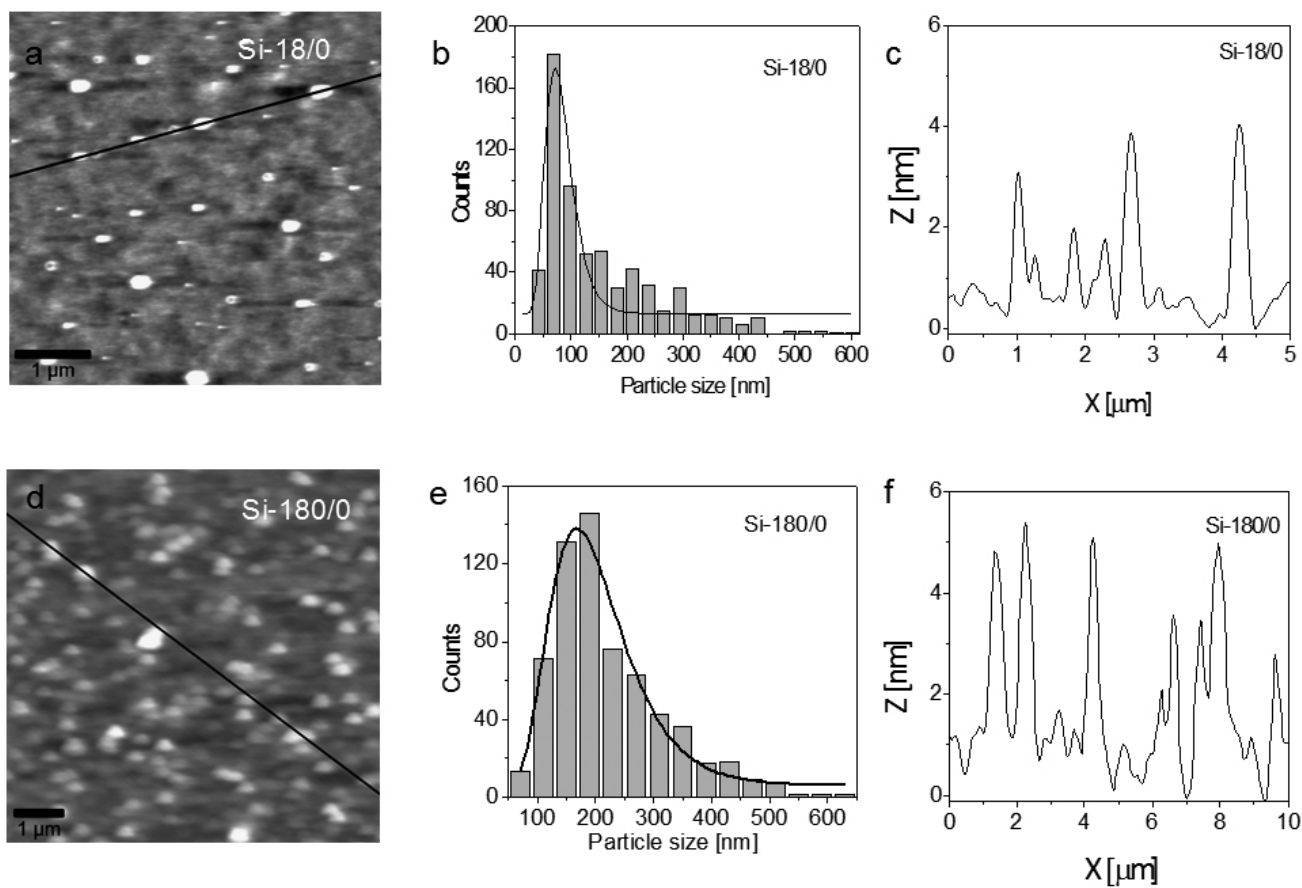

Figure 1. AFM images for $\mathrm{Ag}$ particles deposited onto n-type (100) Si prepared using $\mathrm{AgNO}_{3} 5 \% \mathrm{~m} / \mathrm{m}$ and $\mathrm{HF} 5 \mathrm{M}$ solution (step 1) at (a) $18 \mathrm{~s} \mathrm{(Si-18/0)}$ and (d) $3 \mathrm{~min}$ (Si-180/0). (b) and (e) The mean diameter distribution and Gaussian fitting at $18 \mathrm{~s}$ and $3 \mathrm{~min}$, respectively. (c) and (f) the cross-sectional AFM images for corresponding AFM images indicated by solid line.
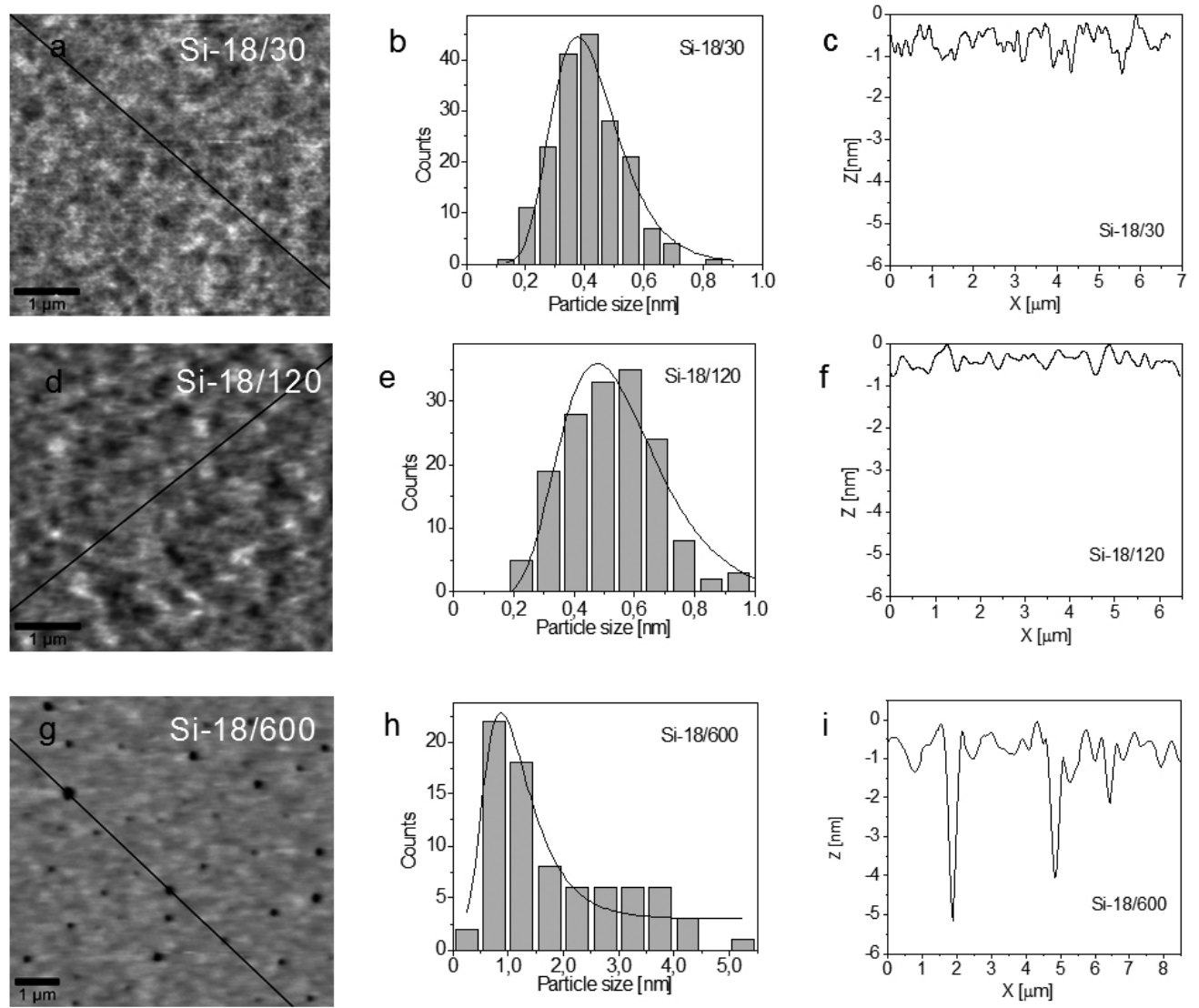

Figure 2. AFM images of a silicon wafer textured by the MACE process at $18 \mathrm{~s}$ in AgNO $5 \% \mathrm{~m} / \mathrm{m}$ and $\mathrm{HF} 5 \mathrm{M}$ solution (step 1) by (a) 30sec (Si-18/30), (d) $120 \mathrm{~s}$ (Si-18/120) and (g) $10 \mathrm{~min}(\mathbf{S i - 1 8 / 6 0 0})$ in $\mathrm{H}_{2} \mathrm{O}_{2} 5 \% \mathrm{~m} / \mathrm{m}$ and $\mathrm{HF}$ $5 \mathrm{M}$ etching solution (step 2). (b), (e) and (f) the mean diameter distribution and Gaussian fitting at $30 \mathrm{~s}, 120 \mathrm{~s}$ and 600 $\mathrm{s}$, respectively. (c), (f) and (h) the cross-sectional AFM images for corresponding AFM images indicated by solid line. 
3.3 X-Ray Diffraction Analysis

Figure 3 shows the X-ray diffraction (XRD) pattern of crystalline silver nanoparticles deposited on n-type (100) Si at 18 second of treatment with of $\mathrm{AgNO}_{3} 5 \% \mathrm{~m} / \mathrm{m}$ and $\mathrm{HF} 5 \mathrm{M}$. The spectrum shows three peaks at $2 \theta=38.2^{\circ}$, $44.5^{\circ}$ and $64.8^{\circ}$, which can be assigned to the (111), (200) and (220) reflections of the face centered cubic (fcc) structure of metallic silver, respectively. The lattice parameter calculated from the XRD pattern is $\mathrm{a}=\mathrm{b}=\mathrm{c}=4.07846 \AA$ in agreement with the literature value of $\mathrm{a}=4.086 \AA$ [21]. The Scherrer equation allows the crystallite size to be estimated. The Scherrer equation used was $\mathrm{D}=$ $0.9 \lambda / \beta \cos \theta$, where $\mathrm{D}$ is the average grain size, $\lambda$ is the radiation wavelength used for the diffraction experiments, $\theta$ is the diffraction angle, and $\beta$ is the full-width at half maximum (FWHM) of the observed peaks. The strongest diffraction peak (111) was used to calculate the crystallite size. The result of crystallite size for the silver sample immersed in $\mathrm{AgNO}_{3} 5 \% \mathrm{~m} / \mathrm{m}$ and $\mathrm{HF} 5 \mathrm{M}$ solution for 18 second was $62 \mathrm{~nm}$, sample $\mathbf{S i - 1 8 / 0}$.

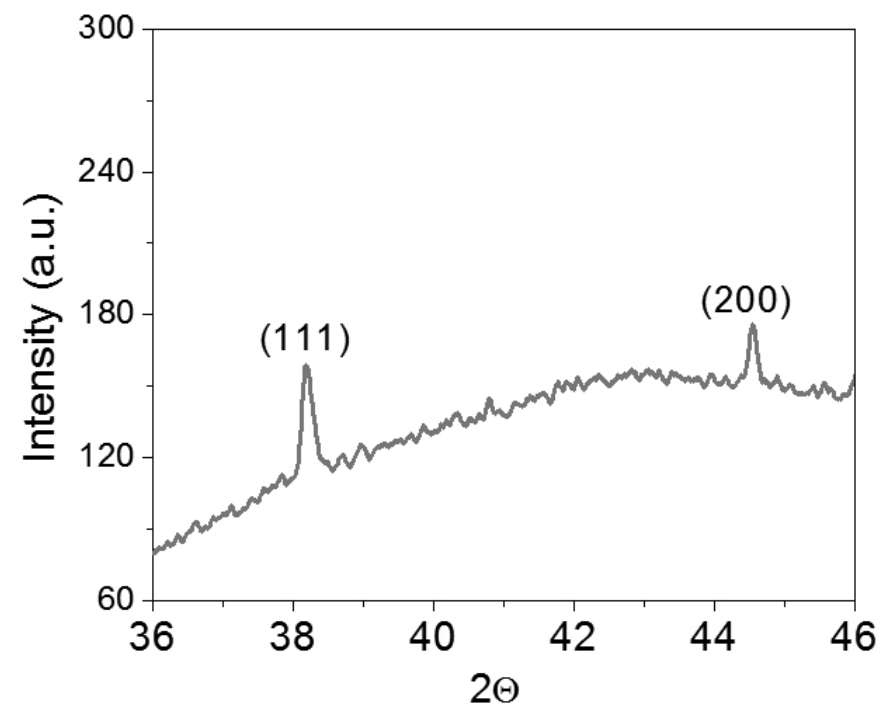

Figure 3. XRD patterns (111) and (200) of silver nanoparticle onto n-type (100) $\mathrm{Si}$ at $18 \mathrm{~s}$ of treatment with of $\mathrm{AgNO}_{3} / \mathrm{HF}$ solution $(\mathbf{S i}-\mathbf{1 8} / \mathbf{0})$.

\subsection{Spectral reflectance}

The spectral reflectance for the Si (100) and silicon solar cell are plotted in Figure 4a. The graph show the reflectance of the samples after the exposure in, firstly, an $\mathrm{AgNO}_{3} / \mathrm{HF}$ solution for $18 \mathrm{~s}$ and, secondly, in a $\mathrm{H}_{2} \mathrm{O}_{2} / \mathrm{HF}$ solution for 0,30 and $120 \mathrm{~s}$, respectively. For the $\mathrm{Si}$ (100) wafer samples (Si-18/0, Si18/30 and Si-18/120), the reflectance values are lower than those of a polished Si wafer $(\mathbf{S i - 0 / 0})$ within a range of wavelengths between 300 and 800 $\mathrm{nm}$. The presence of silver nanoparticles on the surface of the silicon wafer sample (Si18/0) is effective in reducing the reflectivity. This effect is similar to reported results using $\mathrm{Au}$ nanoparticles on a planar Si surface and a SiNP textured surface [22]. It is also noted that the different reflection behavior from a polished silicon wafer for wavelengths over $550 \mathrm{~nm}$ is similar to that which is reported by other groups [23]. Figure $4 \mathrm{~b}$ shows the measured reflectance spectra of porous arrays textured in a commercial silicon solar cell with $18 \mathrm{~s}$ of $\mathrm{AgNO} / \mathrm{HF}$ treatment in equal conditions and etching time. The presence of metallic nanoparticles on surface of commercial silicon solar cell ( $\mathbf{S C - 1 8 / 0 )}$ is effective in reducing the reflectivity, similar to that observed for the Si wafer (Figure 4a). However, the reflection in solar cell samples for wavelengths over $550 \mathrm{~nm}$ the reflectivity is closer. As expected, the reflectivity in solar cells with the etching solution treatment (step 2) is reduced in the wavelength range where solar radiation has a maximum intensity when compared with the solar cell reference (SC-Ref). The weighted mean reflection is less than $10 \%$ in the range of 300 to $800 \mathrm{~nm}$ for the modified solar cell samples. For both the $\mathrm{Si}$ wafer and commercial silicon solar cell, the decreased reflectance of the structure is attributed to increased roughness of the silicon wafer and silicon solar cell due to the texturing of the sample surface. An improved suppression in the reflectance is observed due to the nanoporous structure in both sets of samples.
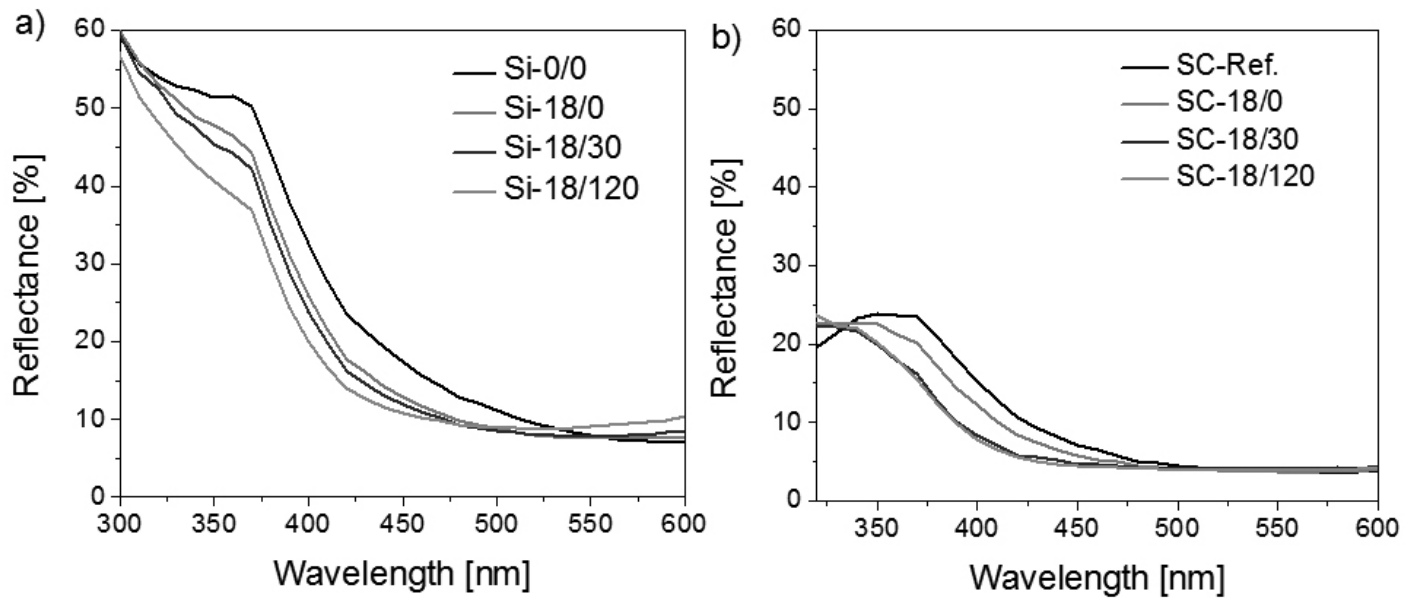

Figure 4. Optical reflectance spectra of (a) a Si wafer and (b) a commercial silicon solar cell taken at $18 \mathrm{~s}$ with $\mathrm{Ag} / \mathrm{HF}$ (step 1) at 0,30 , and 120 seconds in etching solution (step 2). 


\subsection{I-V Curve}

To measure the I-V curves of the sample, we fabricated arrays textured onto the surface of commercial silicon solar cells with different etching times. Samples were prepared at different etching times and their electrical performances were measured under standard test conditions, with an incident radiation power density of $1000 \mathrm{~W} / \mathrm{m}^{2}$. The $J-V$ characteristics for the solar cells without treatment, samples with only silver nanoparticles, and samples with porous texturing are plotted in Fig 5. The solar cell parameters such as open circuit voltage $(V \mathrm{oc})$, short circuit current density $\left(J_{\mathrm{sc}}\right)$, fill factor $(F F)$ and power conversion efficiency are presented in Table 2 . The reference solar cell (SC-Ref) shows an open circuit voltage of $525 \mathrm{mV}$, a short-circuit current density of $36.9 \mathrm{~mA} / \mathrm{cm}^{2}$ and an efficiency of $12.7 \%$. An increase in efficiency was observed in the samples at $18 \mathrm{~s}$ in step 1 and 0 to $300 \mathrm{~s}$ in step 2, with $\Delta \eta 0.3-0.6$. It is observed that the incorporation of $\mathrm{Ag} \mathrm{NP}^{\prime} s$ in sample SC$18 / 0$ produced a $0.6 \%$ increase in efficiency compared to SC-Ref under AM $1.5 \mathrm{G}$ illumination. This effect is attributed at an increase of the local electric field strength and the enhanced light scattering. An improvement in the energy conversion efficiency is reported by Ag nanoparticles in planar monocrystalline silicon solar cells [24]. The samples with 18 seconds of immersion in silver nitrate/HF solution (step 1) and 30 seconds (SC-18/30) of $\mathrm{H}_{2} \mathrm{O}_{2} / \mathrm{HF}$ solution (step 2) treatment shows a resulting in power conversion efficiency of $13.5 \%$ In this sense, the surface of the sample of silicon solar cells textured with silver-assisted etching (SC-18/30) increases $J_{\mathrm{Sc}}$ by $0.9 \mathrm{~mA} / \mathrm{cm}^{2}$, compared to a standard silicon solar cell and leads to a $0.8 \%$ increase in absolute efficiency. This increase in electrical efficiency is attributed to a decrease in the reflectivity of the solar cell with pores on the surface. Li et al. discussed that the light absorption can be significantly enhanced even with low aspectratio surface texturing [25]. In this same sense, the use of texturing without introducing a high number of surface defects shows a potential application for these processes in manufacture of photoconversion devices [26]. Ouyang et al. established that the incorporation of Ag nanoparticles on the silicon surface has no adverse effect because it does not increase the surface recombination [27] Fig. 5 shows I-V curves of the solar reference of commercial silicon solar cell (SC-Ref) and textured solar cells at different etching times at the step 2. Where our best nanostructured solar cell from black silicon SC-18/30 is included in both inserts for best comparison. A decrease in efficiency is observed at higher processing times in etching solution (step 2). Samples with greater depths show relatively poor electrical performance despite having better optical absorption. Silicon solar cells treated at $18 \mathrm{~s}$ in step 1 with more than $1 \mathrm{~min}$ in the catalytic step ( $\operatorname{step} 2$ ) show poor electrical performance (see Table 2 ). It has been reported that the nanoporous structure increases superficial area of silicon surface and induces a higher surface recombination velocity associated with this increased area [28].

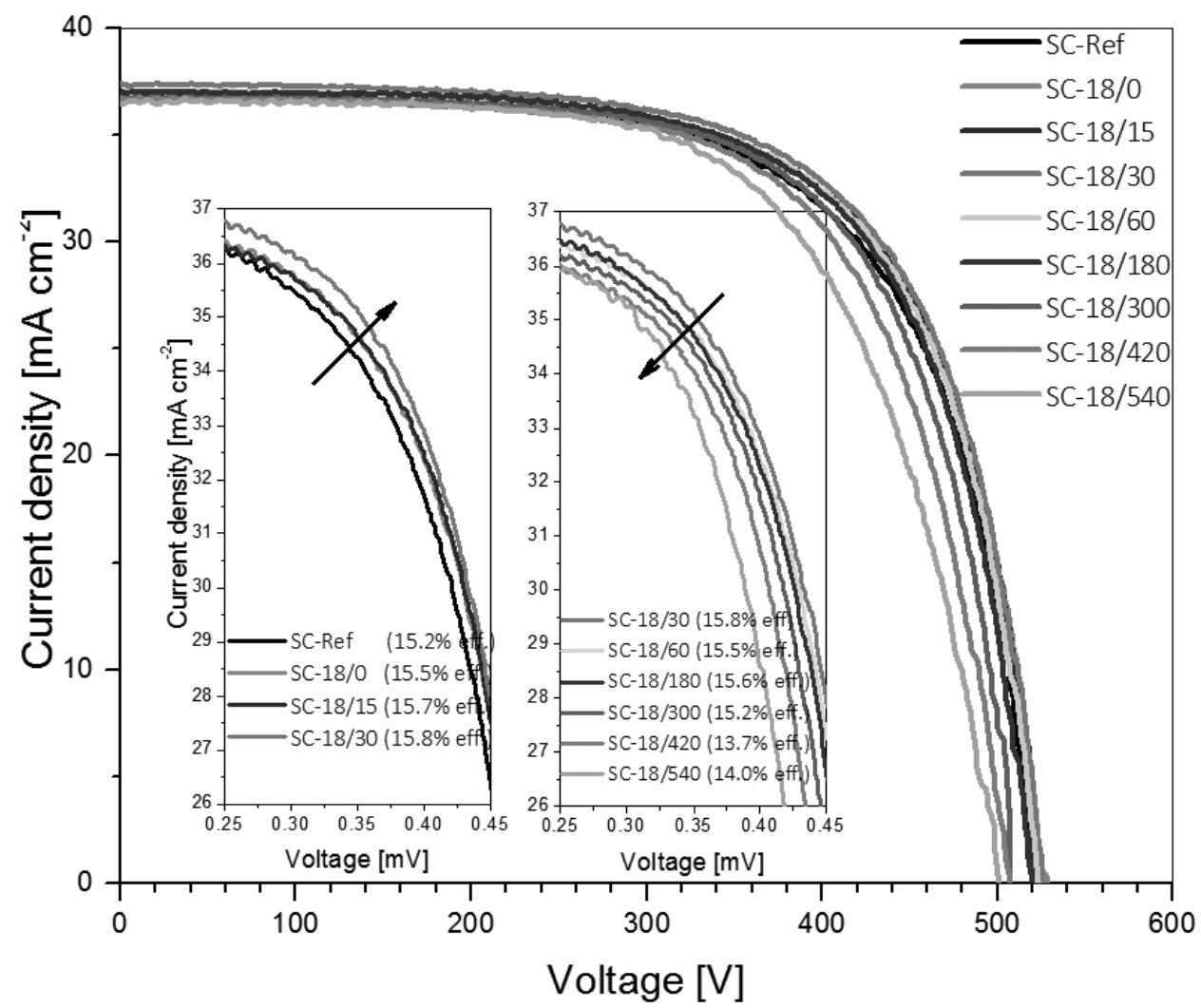

Figure 5. Illuminated $J-V$ characteristics curves for commercial silicon solar cells (SC-Ref) used as a reference and solar cell samples with silver nanoparticles and porous texturing.

For a better understanding on how the efficiency changes versus the absorptance of the cell, $\alpha$, the integral value of the spectral absorptance is included in Fig 6 . The spectral absorptance, $\alpha_{\lambda}$, is calculated from the spectral reflectance measurements, $\rho_{\lambda}$, assuming opaque samples $\alpha_{\lambda}=\left(1-\rho_{\lambda}\right)$ Then, $\alpha_{\lambda}$ is multiplied by the spectral global irradiance reference, $\mathrm{G}$, as described in ASTM G173-3 [29]. Finally, the integral is calculated according the following expression (1):

$$
\alpha=\int_{\lambda_{1}}^{\lambda_{2}}\left(1-\rho_{\lambda}\right) G_{\lambda} d \lambda
$$

Where $\lambda_{1}$ and $\lambda_{2}$ are the limits of the integral, $\rho_{\lambda}$ is the measured spectral reflectance, $G_{\lambda}$ is the reference spectrum and is the absorptance in the spectral range of the integral. As expected, at long etching times an increase in $\alpha$ is observed due to the light-trapping properties. However, the efficiency of the modified solar cell is reduced. This effect is associated to the competition between improved absorption and increased surface recombination, suggesting that this enhanced absorption could be dominated by surface recombination. 
Table 2. Measured cell parameters under AM 1.5 irradiance for modified silicon solar cell treated at $18 \mathrm{~s}$ in step 1 with different etching time in step 2.

\begin{tabular}{|c|c|c|c|c|c|}
\hline Sample & $J_{\text {sc }}\left[\mathrm{mA} \mathrm{cm}^{-2}\right]$ & $V$ oc $[\mathrm{mV}]$ & Fill factor [\%] & Efficiency[\%] & $\Delta \eta$ \\
\hline SC-Ref & 36.9 & 525 & 67.0 & 12.7 & 0.0 \\
\hline SC-18/0 & 36.9 & 527 & 68.3 & 13.3 & 0.6 \\
\hline SC-18/15 & 37.1 & 530 & 68.7 & 13.4 & 0.6 \\
\hline SC-18/30 & 37.8 & 529 & 67.5 & 13.5 & 0.8 \\
\hline SC-18/45 & 36.8 & 524 & 69.1 & 13.2 & 0.5 \\
\hline SC-18/60 & 36.9 & 524 & 68.5 & 13.3 & 0.5 \\
\hline SC-18/120 & 37.1 & 523 & 68.5 & 13.3 & 0.6 \\
\hline SC-18/180 & 37.2 & 523 & 68.4 & 13.3 & 0.6 \\
\hline SC-18/240 & 37.1 & 520 & 68.3 & 13.3 & 0.5 \\
\hline SC-18/300 & 37.1 & 515 & 67.9 & 13.0 & 0.3 \\
\hline SC-18/360 & 37.0 & 513 & 67.3 & 12.8 & 0.1 \\
\hline SC-18/420 & 36.6 & 508 & 62.8 & 12.6 & -0.1 \\
\hline SC-18/480 & 37.5 & 506 & 65.7 & 12.5 & -0.3 \\
\hline SC-18/540 & 36.8 & 502 & 65.0 & 12.0 & -0.7 \\
\hline SC-18/600 & 36.6 & 499 & 63.8 & 11.6 & -1.1 \\
\hline
\end{tabular}

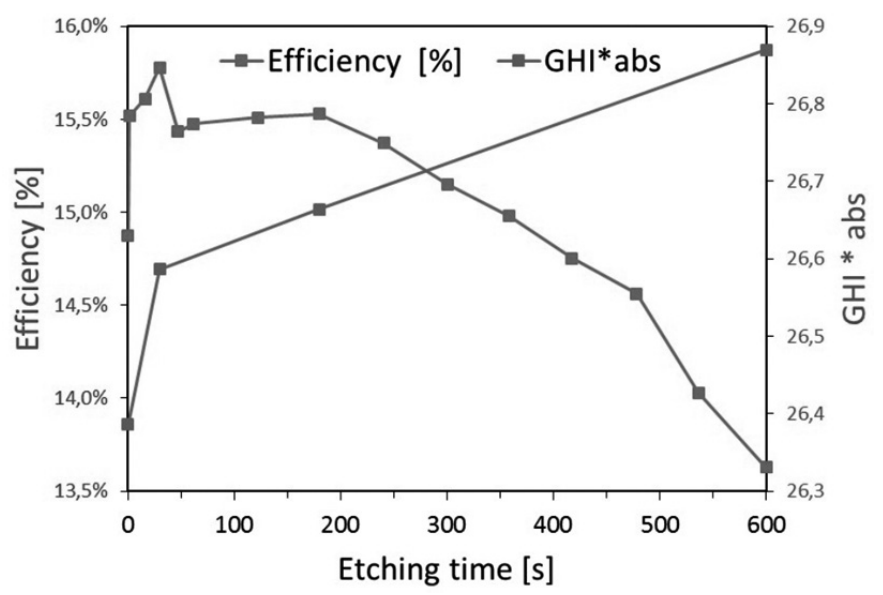

Figure 6. Plot of efficiency (\%) as function of etching time at 18 second of $\mathrm{Ag} / \mathrm{HF}$ solution treatment (step 1), here our best nanostructured solar cell from black silicon at 30s (step 2) is found (SC-18/30). The integral value of the spectral absorptance is included.

\section{CONCLUSIONS}

In summary, we prepared a textured surface through a two-step, silverassisted chemical etching process on silicon wafers and commercial silicon solar cells. Silver nanoparticles were synthesized by wet chemical process, and both substrates were immersed in a solution containing $\mathrm{HF}$ and $\mathrm{H}_{2} \mathrm{O}_{2}$. The Ag NP's show approximately spherical grains on the Si wafer. The AFM image showed a large number of pores with a uniform size distribution on the surface of the substrate. An increase in particle size at longer times with silver ion solution (step 1) and an increase in depth at longer etching times (step 2 ) is observed in the topological analysis. For the Si wafer and commercial silicon solar cells, the reflectance measurements results showed that the total reflectance is reduced at longer etching times (step 2). We found that the optimum experimental conditions required in order to obtain the best efficiency in solar cells was achieved by using an immersion of $18 \mathrm{~s}$ in the silver salt acid solution and $30 \mathrm{~s}$ in the etching solution (SC-18/30). A decrease in the values of the photocurrent efficiency is observed in samples with longer etching time. These results suggest that this loss in efficiency is associated with the high depth of the pores on the solar cell due to the increased surface recombination associated with the increased surface area. Nevertheless, this procedure shows good potential to increase solar cell efficiency while minimizing manufacturing costs for these devices.

\section{ACKNOWLEDGMENTS}

This work was supported by Proyecto Anillo ACT1204, Programa de Investigación Asociativa (PIA), CONICYT and FONDECYT N ${ }^{\circ} 1130984$. The authors acknowledge the generous financial support provided by the Education Ministry of Chile Grant PMI ANT1201, the Fondecyt Project 3160190, as well as CONICYT/ FONDAP/ 15110019 "Solar Energy Research Center" SERCChile.

\section{REFERENCES}

[1] P. Spinelli, M.A. Verschuuren, and A. Polman, Nature Communications 3 (2012) 1 .

[2] H. A. Macleod, Thin-film optical filters (American Elsevier Pub. Co., New York, 1969).

[3] J. de Boor, N. Geyer, J.V. Wittemann. U. Gosele, and V. Schmitdt, Nanotechnology 21, (2010). Y. Wu and P. Yang, J. Am. Chem. Soc. 123 (2001) 3165. S. Kodambaka, J. B. Hannon, R. M. Tromp, and F. M. Ross, Nano Lett. 6 (2006) 1292. T. Stelzner, M. Pietsch, G. Andrä, F. Falk, E. Ose and S. Christiansen, Nanotechnology 19 (2008) 1.

[4] a) D.S. Ruby, W.K. Scubert, J.M. Gee, and S.H. Zaidi, U.S. Patent No. 6091021, (2000). b) A. V. Whitney, B. D. Myers, and R. P. Van Duyne, Nano Lett. 4 (2004) 1507.

[5] H. D. Tong, H. V. Jansen, V. J. Gadgil, C. G. Bostan, E. Berenschot, C. J. van Rijn, and M. Elwenspoek, Nano Lett. 4 (2004) 283.

[6] a) J. Shao, E. A. Josephs, C. Lee, A. Lopez, and T. Ye, ACS Nano 7 (2013) 5421. b) A. Prasad, S. Balakrishnan, S. K. Jain, and G.C. Jain, Electrochem. Soc. 129 (1982) 596. c) T. Homma, H. Sato, K. Mori, T. Osaka, and S. Shoji, J. Phys. Chem. B 109 (2005) 5724.

[7] R. Torres, V. Vervisch, M. Halwax, T. Sarnet, P. Delaporte, M. Sentis, J. Ferreira, D. Barakel, S. Bastide, F. Torregrosa, H. Etienne, and L. Roux, Journal of Optoelectronics and Advanced Materials 12 (2010) 621.

[8] M. Bechelany, E. Berodier, X. Maeder, S. Schmitt, J. Michler, and L. Philippe, Appl. Mater. Interfaces 3 (2011) 3866.

[9] H. Han, Z. Huang, and W. Lee, Nanotoday 9 (2014) 271. H.C. Yuan, V. E. Yost, M. R. Page, L. Roybal, B. To, P. Stradins, D. L. Meier, and H. M. Branz, 34th IEEE Photovoltaic Specialists Conference, 141 (2009). R. Chaoui, B. Mahmoudi, and Y.S. Ahmed, Physica Status Solidi A 205 (2008) 1724.

[10] Y. Qu, L. Liao, Y. Li, H. Zhang, Y. Huang, and X. Duan, Nano Lett. 9 (2009) 4539.

[11]H. A. Atwater and A. Polman, Nat. Mater. 9 (2010) 205. 
[12]X. Wang, J. Wang, and H. Wang, Solar Energy 101 (2014) 100.

[13]K.R. Catchpole and A. Polman, Opt. Express 16 (2008) 21723.

[14] X. Liu, P. R. Coxon, M. Peters, B. Hoex, J. M. Cole, and D. J. Fray, Energy Environ. Sci. 7 (2014) 3223.

[15] Y. Liu, G. Ji, J. Wang, X. Liang, Z. Zuo, and Yi Shi, Nanoscale Research Letters 7 (2012) 663.

[16] M. Algasinger, M. Bernt, S. Koynov, and M. Stutzmann, J. Appl. Phys. 115 (2014) 164308.

[17] S. Bastide, T. Nychyporuk, Z. Zhou, A. Fave, and M. Lemiti, Solar Energy Materials \& Solar Cells 102 (2012) 26.

[18]Z. Huang, T.Shimizu, S. Senz, Z. Zhang, N. Geyer, and U. Gösele, J. Phys. Chem. C 114 (2010) 10683.

[19] K. Tsujino and M. Matsumura, Electrochimica Acta 53 (2007) 28.

[20]M. Lee and D. Khang, RSC Adv. 3 (2013) 26313.

[21] Joint Committee on Powder Diffraction Standars, silver file No. 04-0783.

[22] P.R. Pudasaini and A. Ayon, Microelectronic Engineering 110 (2013) 126.
[23]L. Zeng, X. Yu, Y. Han, and D. Yang, Journal of Nanomaterials 2012 (2012) 6 .

[24] N. F. Fahim, B. Jia, Z. Shi, and M. Gu, Opt. Express 20 (2012) 694.

[25] J. Li, H. Y. Yu, Y. Li, F. Wang, M.Yang; and S. M. Wong, Appl. Phys. Lett. 98 (2011) 21905.

[26] Y. Liu, S.H. Sun, J. Xu, L. Zhao, H.C.Sun, L. Li, W.W.Mu, L. Xu, and K. J. Chen, Opt. Express 19 (2011) 1051.

[27]Z. Ouyang, S.Pillai, Fi.Beck, O. Kunz, S. Varlamov, K. R. Catchpole, P. Campbell, and M.A. Green, Applied physics letters 96 (2010) 261109.

[28]T. Yehua; Z. Chunlan ; W. Wenjing; Z. Su; Z. Yan; Z. Lei; L. Hailing; Y. Baojun; C. Jingwei, F. Jianming, and C. Hongbin, J. Semicond. 33 (2012) 064007.

[29] American Society for Testing and Materials, "ASTM G173 - 03 Standard Tables for Reference Solar Spectral Irradiances: Direct Normal and Hemispherical on $37^{\circ}$ Tilted Surface," 2012. [Online]. Available: https:// www.astm.org/Standards/G173.htm. [Accessed: 09-Sep-2016]. 